\title{
QUALIDADE DE FRUTOS DO COQUEIRO-ANÃO VERDE FERTIRRIGADO COM NITROGÊNIO E POTÁSSIO ${ }^{1}$
}

\author{
RICARDO ALENCAR DA SILVA², LOURIVAL FERREIRA CAVALCANTE, ${ }^{3,6}$ JOSÉ SIMPLÍCIO DE HOLANDA \\ WALTER ESFRAIN PEREIRA ${ }^{3}$, MÁCIO FARIAS DE MOURA ${ }^{5}$, MIGUEL FERREIRA NETO ${ }^{6}$
}

\begin{abstract}
RESUMO - Em um pomar de coqueiro-anão verde (Cocos nucifera L.) com três anos de idade, um experimento de campo foi desenvolvido no período de abril/2000 a maio/2002, em Parnamirim, Rio Grande do Norte, para avaliar os efeitos do nitrogênio e do potássio aplicados via fertirrigação sobre o peso médio dos frutos, o volume, o pH, o teor de sólidos solúveis e a condutividade elétrica da água de coco. Os tratamentos consistiram da combinação através da matriz experimental de Plan Puebla, de cinco doses de N e cinco doses de K, ambos variando de 135 a 2.565 g planta ${ }^{-1}$ ano $^{-1}$. O delineamento experimental foi o de blocos ao acaso, com quatro repetições. As doses de $\mathrm{N}$ e $\mathrm{K}$ afetaram o peso médio dos frutos, sendo que o maior peso médio, $2,23 \mathrm{~kg}$, foi obtido com as doses de 881,31 g de N planta ${ }^{-1}$ ano $^{-1}$ e $1.689,48 \mathrm{~g} \mathrm{de} \mathrm{K} \mathrm{planta}^{-1}$ ano $^{-1}$. Também se observou efeito no volume da água de coco para os dois nutrientes. A dose de máxima eficiência física foi 818,94 $\mathrm{g} \mathrm{de} \mathrm{N} \mathrm{planta}^{-1} \mathrm{ano}^{-1} \mathrm{e}^{1.487,38}$ g de $\mathrm{K}_{\text {planta }}{ }^{-1}$ ano $^{-1}$, atingindo 417,81 $\mathrm{mL}$ de volume. Apenas as doses de $\mathrm{K}$ influíram no pH da água de coco. As doses de $\mathrm{N}$ e $\mathrm{K}$ aplicadas afetaram o teor de sólidos solúveis da água de coco de maneira linear, decrescente e crescente, respectivamente. As doses de $\mathrm{N}$ tiveram efeito linear decrescente, e as doses de $\mathrm{K}$, efeito quadrático sobre a condutividade elétrica da água de coco.
\end{abstract}

Termos para indexação: Cocos nucifera, fertirrigação, água de coco.

\section{FRUITS QUALITY OF GREEN DWARF COCONUT FERTIRRIGATION WITH NITROGEN AND POTASSIUM}

ABSTRACT - Field experiments were conducted to investigate the effect of fertirrigation using nitrogen and potassium on the average weight of coconut and $\mathrm{pH}$, soluble solids content, volume and electrical conductivity of coconut water. The experiment was carried out in a three-year old experimental field of green dwarf coconut (Cocos nucifera) located at Parnamirim, RN between April 2000 and May 2002. A Plan Puebla matrix was used in order to generate experimental groups with different combinations of nitrogen and potassium concentrations within a range of 135 $\mathrm{g}$ plant $^{-1}$ year $^{-1}$ to $2565 \mathrm{~g} \mathrm{plant}^{-1}$ year $^{-1}$. The statistical design consisted of randomized blocks with four replications. Nitrogen and potassium

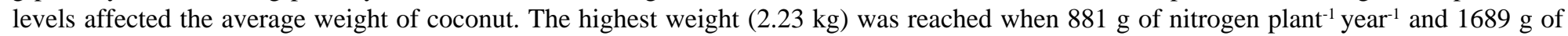
potassium plant ${ }^{-1}$ year $^{-1}$ were used. Coconut water volume was also affected by both nutrients, since the maximum volume observed (417.75 mL) was found when $818 \mathrm{~g}$ of nitrogen plant ${ }^{-1}$ year $^{-1}$ and $1487 \mathrm{~g}$ of potassium plant ${ }^{-1}$ year $^{-1}$ were tested. Nitrogen and potassium levels also demonstrated a linear effect on the soluble solids content of coconut water, where nitrogen had a negative and potassium a positive effect on it. A negative linear effect was observed between nitrogen concentration and electrical conductivity of coconut water, while it was observed that potassium levels showed a quadratic effect on this same parameter.

Index terms: Cocos nucifera, fertirrigation, coconut water.

\section{INTRODUÇÃO}

A água de coco é uma solução estéril que, mesmo contendo mais de $90 \%$ de água, é um líquido rico em nutrientes, proteínas, açúcares, vitaminas e gorduras neutras, além de possuir substâncias promotoras do crescimento (Jayaleskshmy et al., 1998). A composição dos aminoácidos da água de coco apresenta semelhança à do leite, mas possui maior porcentagem de arginina, alanina, cistina e serina. Em alguns países onde o déficit nutricional é elevado, a água de coco é utilizada para substituir produtos protéicos. Na Índia, a água de coco fermentada é utilizada como suplemento alimentar nas escolas, e tem promovido aumentos na aprendizagem e na estatura das crianças (Aragão et al., 2001).

As frutas, apesar de exercerem destacada importância à nutrição humana, sobretudo em vitaminas e sais minerais, devem possuir atributos externos e internos que garantam sua qualidade e aceitabilidade pelo consumidor. A melhoria da qualidade dos frutos de determinada frutífera pode ser obtida tanto pelo melhoramento genético como pelo manejo adequado da cultura, no qual se destacam o fornecimento balanceado de água e de nutrientes, o controle de plantas invasoras e o monitoramento fitossanitário. Nesse sentido, programas de adubação têm sido mais efetivos no que se refere à produção total por área ou a produtividade, sem dispensar a mesma importância para a qualidade do produto colhido. Por isso, muitas vezes, há perdas de qualidade dos frutos, que assumem importância conforme a finalidade da produção. Desta forma, a fertilização do solo e a nutrição mineral das plantas exerce efeito quantitativo e qualitativo na produção da grande maioria das plantas cultivadas (Malavolta et al., 1997; Aragão et al., 2002).

As adubações nitrogenadas e potássicas apresentam grande importância para várias fruteiras, uma vez que interferem não só na quantidade produzida, mas também na qualidade do fruto. O nitrogênio e o potássio são os nutrientes que têm apresentado maiores respostas em termos de qualidade dos frutos. Altas doses de nitrogênio reduzem o teor de sólidos solúveis do suco dos frutos. Entretanto, doses mais elevadas de potássio têm aumentado esse teor na maioria das plantas estudadas, indicando que o balanço de nitrogênio e de potássio é extremamente importante para a qualidade dos frutos (Araújo, 2001). Em trabalho realizado com coqueiro-anão, Ferreira Neto (2005) constatou efeito do nitrogênio sobre o volume, o $\mathrm{pH}$ e o teor de sólidos solúveis, e do potássio sobre a condutividade elétrica e o teor de sólidos solúveis da água de coco. Ao avaliar doses de NPK em coqueiro-anão no Estado de São Paulo, Teixeira et al. (2005) observaram que a massa média dos frutos e o volume da água de coco responderam positivamente ao $\mathrm{K}$ e negativamente ao $\mathrm{N}$.

O trabalho teve como objetivo avaliar a influência da adubação com $\mathrm{N}$ e $\mathrm{K}$ via água de irrigação na massa média dos frutos, no volume da água de coco, no $\mathrm{pH}$, no teor de sólidos solúveis e na

\footnotetext{
${ }^{1}$ (Trabalho 131-2005). Recebido: 18-08-2005. Aceito para publicação: 23-06-2006. Parte do Trabalho de Tese do primeiro autor, apresentada ao Centro de Ciências Agrárias - CCA/UFPB.

${ }^{2}$ Professor da EAJ/UFRN. Avenida Jundiaí, s/n CEP: 59280-000. Macaiba-RN. Brasil. E-mail: ralencarsilva@ yahoo.com.br.

${ }^{3}$ Professor do CCA/UFPB. Areia, PB. CEP: 58397-000. E-mail: lofeca@cca.ufpb.br. wep@cca.ufpb.br

${ }^{4}$ Pesquisador EMBRAPA/EMPARN Caixa Postal 188, CEP: 59020-390, Natal (RN). simplicioemparn@rn.gov.br. miguelfneto@zipmail.com.br.

${ }^{5}$ Doutorando do PPGA/CCA/UFPB. Areia - PB. CEP: 58397-000. E-mail: maciof@yahoo.com.br.

${ }^{6}$ Bolsista do CNPq.
} 
condutividade elétrica da água de coco.

\section{MATERIAL E MÉTODOS}

O trabalho foi realizado na Fazenda Jiqui, pertencente à Empresa de Pesquisa Agropecuária do Rio Grande do Norte (EMPARN), Parnamirim-RN, em um pomar de coqueiro-anão com três anos de idade, no período de abril/2000 a maio/2002. O solo no local do experimento é profundo, bem drenado, classificado como Neossolo Quartzarênico Órtico típico (EMBRAPA, 1999), e possuia os atributos químicos: $\mathrm{pH}=5,9 ; \mathrm{Al}=0,10 \mathrm{cmol}_{c} \cdot \mathrm{dm}^{-3} ; \mathrm{Ca}=0,67 \mathrm{cmol}_{c} \cdot \mathrm{dm}^{-3} ; \mathrm{Mg}=$ $0,41 \mathrm{cmol} \cdot \mathrm{dm}^{-3} ; \mathrm{K}=18 \mathrm{mg} \mathrm{dm}^{-3} ; \mathrm{P}=3 \mathrm{mg} \mathrm{dm}^{-3} ; \mathrm{Na}=9 \mathrm{mg} \mathrm{dm}^{-3} ; \mathrm{e} \mathrm{V}=$ $37,21 \%$ (EMBRAPA, 1997)

O delineamento experimental foi o de blocos casualizados, com quatro repetições e 10 plantas por parcela, dispostas em linhas. O espaçamento entre plantas foi de 7,5 x 7,5 x 7,5 m (205 plantas/ha) em plantio triangular, numa área de 1,6 ha. Os tratamentos consistiram da combinação de cinco doses de $\mathrm{N}$ e cinco doses de $\mathrm{K}$, utilizando-se da matriz experimental de Pan Puebla III modificada (Leite, 1984), no esquema fatorial: $2^{2}+(2 \times 2)+1+1$. Utilizou-se a uréia $(44 \%$ de $\mathrm{N})$ como fonte de $\mathrm{N}$ e o cloreto de potássio $\left(58 \%\right.$ de $\left.\mathrm{K}_{2} \mathrm{O}\right)$ como fonte de $\mathrm{K}$. As doses de $\mathrm{N}$ e K variaram de 135 a $2.565 \mathrm{~g} \mathrm{planta}^{-1}$ ano $^{-1}$, assim combinadas: $810 \mathrm{~g}$ de $\mathrm{N}$ e $810 \mathrm{~g}$ de $\mathrm{K} ; 810 \mathrm{~g}$ de Ne $1.890 \mathrm{~g}$ de K$; 1.890$ $\mathrm{g}$ de $\mathrm{Ne} 810 \mathrm{~g}$ de $\mathrm{K} ; 1.890 \mathrm{~g}$ de Ne 1.890 de $\mathrm{K} ; 135 \mathrm{~g}$ de N e 810 de K; $2.565 \mathrm{~g}$ de N e 1890 de K; $810 \mathrm{~g}$ de N e $135 \mathrm{~g} \mathrm{~K} ; 1.890 \mathrm{~g}$ de N e $2.565 \mathrm{~g}$ de $\mathrm{K} ; 1.350 \mathrm{~g}$ de $\mathrm{N}$ e $1.350 \mathrm{~g}$ de $\mathrm{K} ; 135 \mathrm{~g}$ de $\mathrm{N}$ e $135 \mathrm{~g}$ de $\mathrm{K}$.

Foi feita calagem em toda a área experimental com 2,0 $\mathrm{tha}^{-1}$ de calcário dolomítico, depois foi aplicado gesso superficialmente na dose de $300 \mathrm{~kg} \mathrm{ha}^{-1}$, com o objetivo de promover o caminhamento do mesmo a camadas mais profundas. O calcário e o gesso foram aplicados com a finalidade de elevar a saturação por bases para $70 \%$ (Sobral, 1998). Sessenta dias após a calagem, efetuou-se adubação por planta com: 60 litros de esterco bovino de relação C / N =14/1, $1.800 \mathrm{~g} \mathrm{de}$ superfosfato simples e $300 \mathrm{~g}$ de FTE BR - 12. A adubação foi repetida no ano seguinte.

Para irrigação, utilizou-se a microaspersão, com emissores autocompensantes com vazão de $45 \mathrm{~L} \mathrm{~h}^{-1}$. Em cada linha, foram acoplados dez microaspersores, um para cada planta. Utilizou-se um registro no início de cada linha para possibilitar a aplicação das doses de $\mathrm{N}$ e $\mathrm{K}$ previamente estabelecidas. As doses foram parceladas para o período de um ano e aplicadas semanalmente. No período da estiagem, o fornecimento de água foi feito diariamente pela manhã, e suspenso nos dias em que as precipitações foram superiores a $10 \mathrm{~mm}$. Com base nas necessidades hídricas da cultura estabelecidas por Miranda et al. (1999), adotou-se, no primeiro ano do experimento, uma lâmina de água correspondente a $120 \mathrm{~L} \mathrm{planta}^{-1} \mathrm{dia}^{-1}$, e no segundo, $240 \mathrm{~L}_{\text {planta }} \mathrm{dia}^{-1}$.

Foram realizadas 13 colheitas no período de abril/2001 a maio/ 2002, em intervalos de 21 dias, quando os frutos estavam com sete meses a partir da abertura da inflorescência (Aragão et al., 2001). Após cada colheita, 10 frutos por tratamento foram separados aleatoriamente para pesagem, medição do volume e determinação dos atributos de qualidade da água de coco. A concentração de sais na água de coco foi determinada através da condutividade elétrica com correção para temperatura a $25^{\circ} \mathrm{C}$ (Richards, 1954). Os teores de sólidos solúveis ( ${ }^{\circ}$ Brix) e o pH da água foram obtidos adotando a metodologia proposta pelo Instituto Adolfo Lutz (1985). Os dados foram submetidos à análise de variância e à regressão polinomial, sendo obtidas equações de regressão a 1; 5 e $10 \%$ de probabilidade, pelo teste de F. Os resultados foram expressos através de superfícies de resposta.

\section{RESULTADOS E DISCUSSÃO}

Houve efeito das doses de $\mathrm{N}$ e de $\mathrm{K}$ em relação à massa dos frutos, com os dados ajustando-se melhor ao modelo quadrático
(Figura 1). Os valores oscilaram entre 1,90 e 2,23 kg, sendo os maiores frutos obtidos com as doses de 881,31 g de N planta ${ }^{-1}$ ano $^{-1}$ e 1.689,48 $\mathrm{g}$ de $\mathrm{K}_{\text {planta }}{ }^{-1} \mathrm{ano}^{-1}$. Ao considerar que a massa média do fruto do coqueiro-anão verde aos 7 meses foi $1,55 \mathrm{~kg}$ (Aragão et al.,2002), observou-se que a menor massa obtida com as doses de $\mathrm{N}$ e $\mathrm{K}$ foi acima da média, evidenciando o efeito promissor da fertirrigação na massa dos frutos.

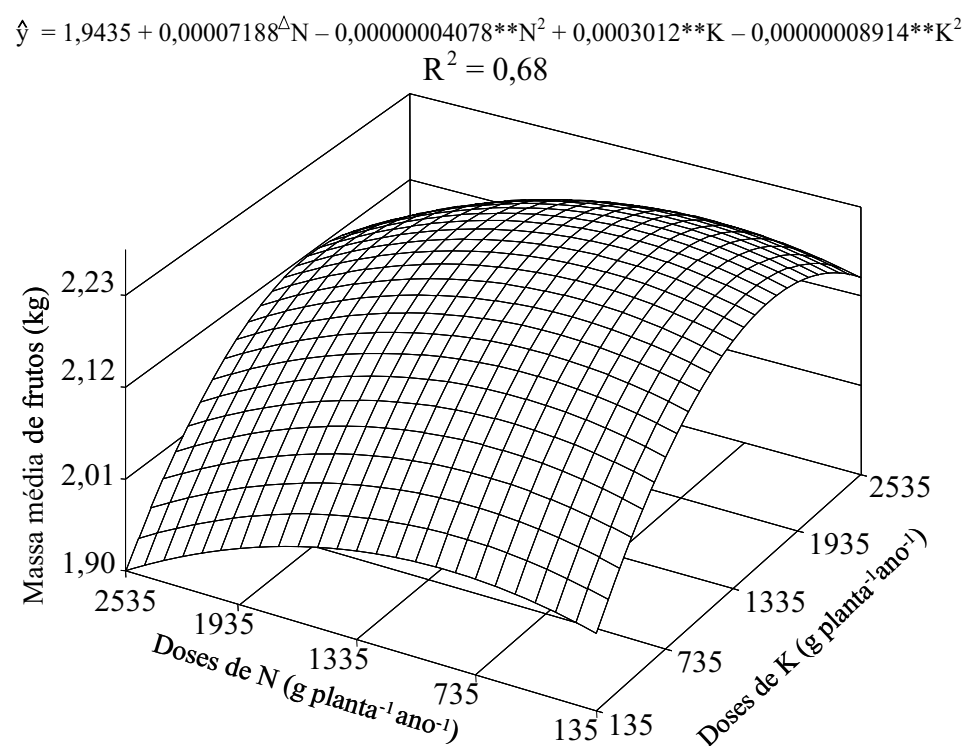

FIGURA 1 - Massa média de frutos de coqueiro-anão verde no quinto ano de cultivo em função das doses de nitrogênio

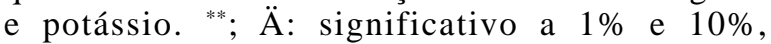
respectivamente, pelo teste de $\mathrm{F}$.

As doses de $\mathrm{N}$ e $\mathrm{K}$ influíram no volume da água de coco, com os dados ajustando-se ao modelo quadrático (Figura 2). Os valores oscilaram de 322,36 a 417,81 mL, sendo o maior volume obtido com

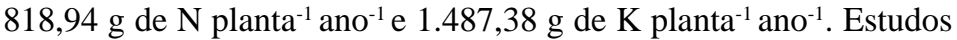
conduzidos por diferentes autores quantificaram o volume de água de coco na época da colheita, com 6 a 7 meses: $258 \mathrm{~mL}$ (EMPARN, 2001), 394,65 mL (Aragão, 2001) e 212 a 310 mL (Aragão et al., 2002). Em plantios fertirrigados na região Nordeste, Bezerra (2002) e Ferreira Neto (2005) obtiveram 481 e $450 \mathrm{~mL}$, respectivamente.

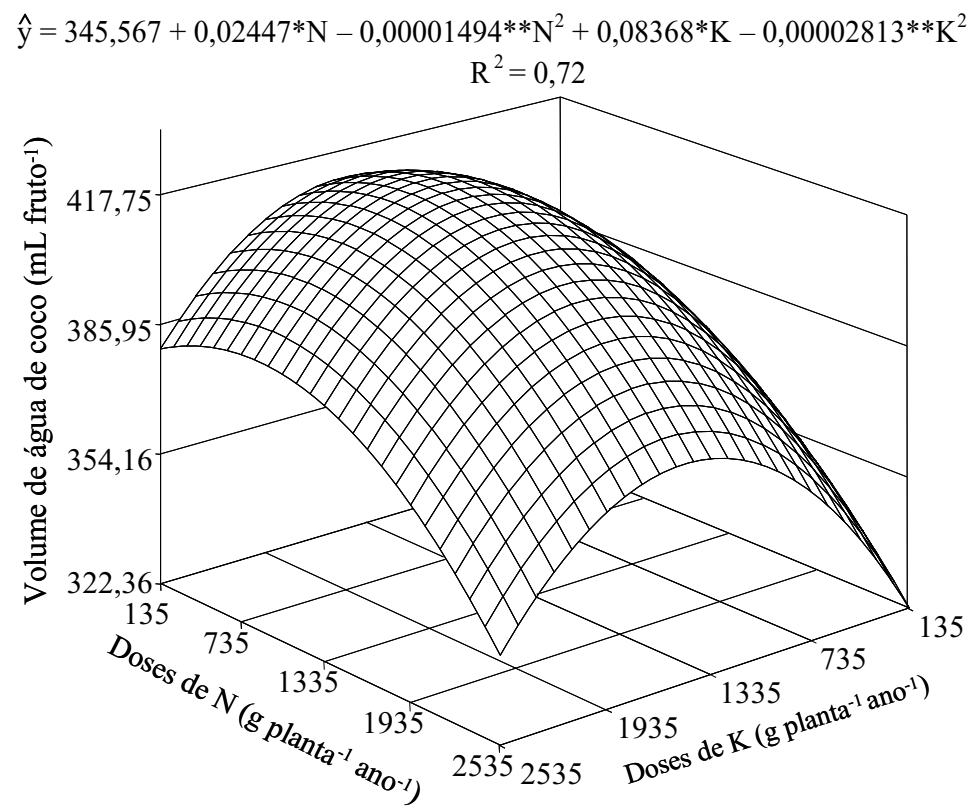

FIGURA 2 - Volume médio de água em frutos de coqueiro-anão verde no quinto ano de cultivo em função das doses de nitrogênio e potássio. *, **; Significativo a $5 \%$ e $1 \%$, respectivamente, pelo teste de $\mathrm{F}$. 
Possivelmente, a resposta da massa e do volume da água dos frutos ocorreu devido à grande demanda do coqueiro-anão verde por K e N (Sobral, 1998), principalmente nos frutos, onde as concentrações desses nutrientes atingem os valores mais elevados em relação às demais partes da planta. A concentração de $\mathrm{K}$ na água de frutos colhidos aos 7 meses foi de 8 a 14 vezes maior que a concentração de $\mathrm{Ca}$, por exemplo (Tavares et al., 1998). Após as doses de $1.689,48$ e $1.487,38 \mathrm{~g} \mathrm{planta}^{-1}$ ano $^{-1}$, observou-se decréscimo da massa e do volume, respectivamente. Segundo Pessarakcli \& Tucker (1988), altas concentrações de cloreto em solução prejudicam a absorção do $\mathrm{N}$, devido à inibição competitiva entre ânions de cloreto e nitrato.

Observou-se a mesma tendência entre a massa dos frutos e o volume da água de coco, e, de acordo com Ferreira Neto (2005), frutos de maior massa apresentam maior cavidade interna e maior volume de água.

Não foi verificado efeito das doses de $\mathrm{N}$ sobre o $\mathrm{pH}$ da água de coco. Apenas as doses de $\mathrm{K}$ influíram significativamente nessa variável, sendo o efeito melhor explicado pelo modelo quadrático (Figura 3). O K apresenta a maior concentração entre os sais minerais presentes na água de coco (Tavares et al., 1998), e maiores concentrações desse elemento no suco celular demandam maior proporção de ácidos dissociados que devem estar presentes para garantir o equilíbrio de cargas negativas e positivas no meio (Malavolta, 1994).

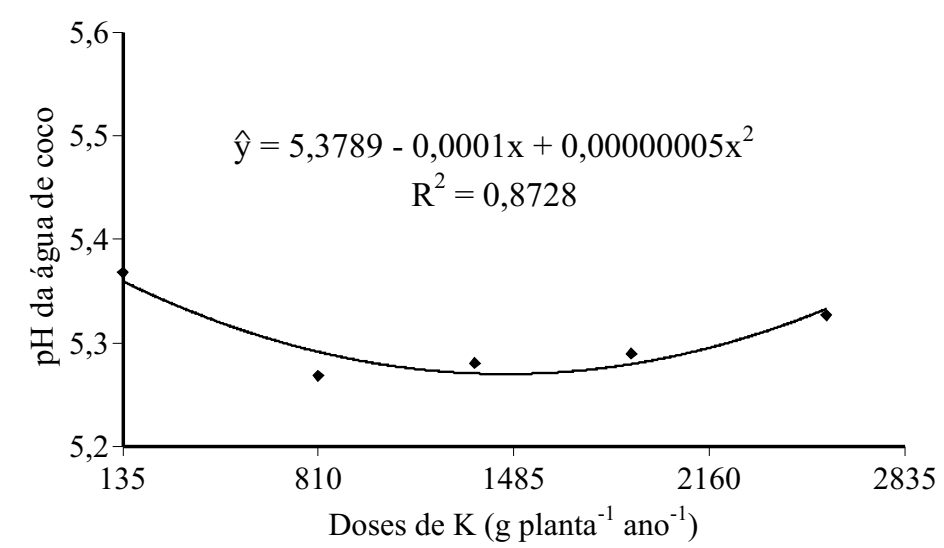

FIGURA 3 - Valores médios de $\mathrm{pH}$ da água em frutos de coqueiroanão verde no quinto ano de cultivo em função das doses de potássio.

A amplitude dos valores de $\mathrm{pH}$ foi baixa, variando de 5,3 a 5,4 entre as doses aplicadas. Em trabalho realizado por Rosa Júnior et al. (2000), o pH em frutos colhidos aos sete meses foi igual a 4,9. Para Tavares et al. (1998), a variação de pH em frutos nessa idade é de 4,7 a 4,9. Segundo esses autores, o sabor doce e a adstringência desejável da água de coco são atingidos com valores de $\mathrm{pH}$ próximos a 5,6, para frutos colhidos aos 8 meses. Entretanto, EMPARN (2001) e Ferreira Neto (2005), em trabalhos conduzidos com fertirrigação na região Nordeste, constataram que o $\mathrm{pH}$ atingiu 5,8 em frutos colhidos com sete meses de idade.

Os teores de sólidos solúveis na água de coco aumentaram linearmente com as doses de $\mathrm{N}$ e $\mathrm{K}$, tendo o $\mathrm{K}$ promovido maior incremento (Figura 4). O N influi na síntese de aminoácidos, carboidratos e outras substâncias orgânicas, e o K exerce efeito sobre o transporte de água na planta e, conseqüentemente, no transporte de assimilados para o fruto (Malavolta et al., 1997). Os valores variaram de 5,64 a 5,88\%, estando de acordo com Tavares et al. (1998), que afirmam que o teor de sólidos solúveis para a água de coco em frutos de coqueiro-anão com sete meses pode variar de 5,2 a 8,9.

Os nutrientes exerceram efeitos diferenciados sobre a condutividade elétrica da água de coco. Verifica-se, na Figura 5, que a $\mathrm{CE}$ diminuiu com o aumento das doses de $\mathrm{N}$ e aumentou com as doses de K. Possivelmente, o cloreto de potássio promoveu a produção de compostos mais solúveis que o nitrogênio, refletindo-se em maior condutividade elétrica. Para as doses estudadas, os valores variaram de 4,45 a 5,97 dS m${ }^{-1}$. Em frutos colhidos aos sete meses de idade, Camboim Neto (2002), ao avaliar o efeito de lâminas de irrigação no coqueiro-anão, verificou uma CE média de $5,57 \mathrm{dS} \mathrm{m}^{-1}$, e Ferreira Neto (2005), ao estudar doses de $\mathrm{N}$ e K via fertirrigação, observou valores que oscilaram entre 5,22 e 5,28 $\mathrm{dS} \mathrm{m}^{-1}$. Devido à escassez de trabalhos na literatura que avaliem a $\mathrm{CE}$, ainda não é possível determinar qual o melhor valor para esta variável, entretanto, para Jayalekshmy et al. (1998), a CE pode ser considerada de grande importância por influir no sabor e no valor nutritivo da água de coco.

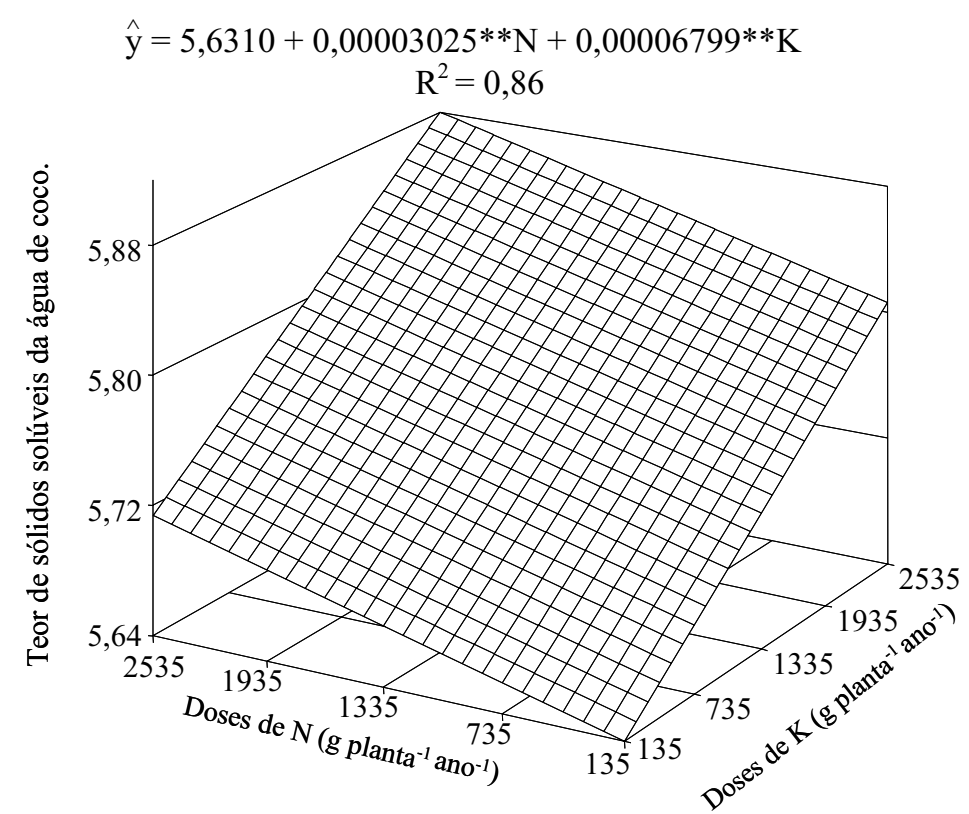

FIGURA 4 - Teores médios de sólidos solúveis da água em frutos de coqueiro-anão verde no quinto ano de cultivo em função das doses de nitrogênio e potássio. **; Significativo a $1 \%$, pelo teste de F.

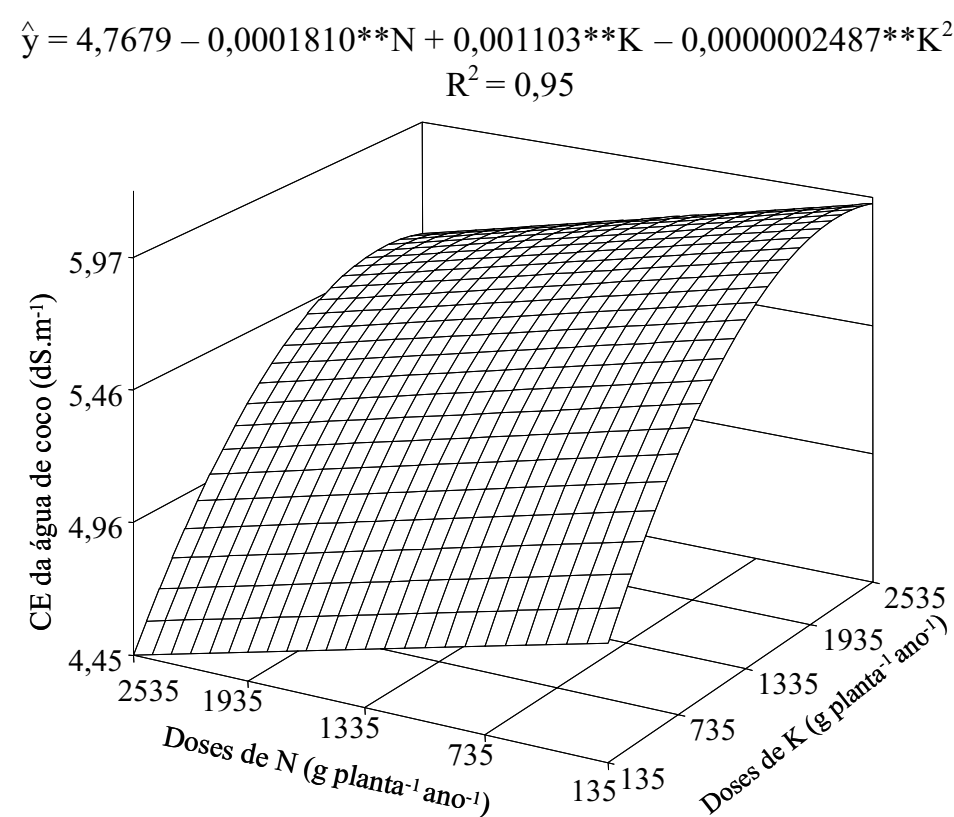

FIGURA 5 - Condutividade elétrica da água em frutos de coqueiroanão verde no quinto ano de cultivo em função das doses de nitrogênio e potássio. **; Significativo a $1 \%$, pelo teste de F.

\section{CONCLUSÕES}

Nas condições em que foi conduzido o trabalho, os dados obtidos evidenciam que: 
A quantidade de uréia e de cloreto de potássio aplicados via fertirrigação influiu significativamente sobre o peso e a qualidade da água dos frutos do coqueiro-anão verde.

\section{REFERÊNCIAS}

ARAGÃO, W. M.; ISBERNER, I. V.; CRUZ, E. M. de. O. Água-de-coco. Aracaju: Embrapa-CPATC, 2001.32p.

ARAGÃO, W. M.; RESENDE, J. M.; CRUZ, E. M. de O.; REIS, C. dos S.; SAGGIN JÚNIOR, O. J.; ALENCAR, J. A. de.; MOREIRA, W. A.; PAULA, F. R. de.; LIMA FILHO, J. M. P. Fruto do coqueiro para consumo natural. In: ARAGÃO, W. M. (Ed.). Coco póscolheita. Brasília: Embrapa - CTATC, 2002. cap. 3, p. 19-25.

ARAÚJO, R. da COSTA. Produção, qualidade de frutos e teores foliares de nutrientes no maracujazeiro amarelo em resposta à adubação potássica. 2001. 103f. Tese (Doutorado em Fitotecnia) Universidade Federal de Viçosa, Viçosa, 2001.

BEZERRA, J. W. T, Efeito da freqüência de irrigação no desenvolvimento radicular e produção do coqueiro anão. 2002. 48f. Dissertação (Mestrado em Irrigação e Drenagem) Universidade Federal do Ceará, Fortaleza, 2002.

CAMBOIM NETO, L. de F. Coqueiro verde: influência de diferentes lâminas de irrigação e de porcentagens de área molhada no desenvolvimento, na produção e nos parâmetros físico químicos do fruto. 2002. $121 \mathrm{f}$. Tese (Doutorado) - Universidade Federal de Viçosa, Viçosa, 2002.

EMBRAPA. Serviço Nacional de levantamento e Conservação de Solos (Rio de Janeiro, RJ). Manual de método de análise de solo. Rio de Janeiro, 1997. 212p.

EMBRAPA. Sistema brasileiro de classificação de solos. Brasília: Serviço de Produção de Informação, 1999. 412p.

EMPARN. Caracterização física do fruto e composição química da água de coco de cultivares anão verde do jiqui, anão amarelo e híbrido PB 121 aos 5, 6, 7, 8 e 9 meses de idade. In: SEMANA INTERNACIONAL DA FRUTICULTURA, FLORICULTURAE AGROINDÚSTRIA, 8., 2001, Fortaleza.

FERREIRA NETO, M. Doses de N e K aplicadas via fertirrigação na cultura do coqueiro-anão (Cocos nucifera l.) anão. 2005. $119 \mathrm{f}$. Tese (Doutorado em Agronomia) - Escola Superior de Agricultura "Luiz de Queiroz", Universidade de São Paulo, Piracicaba, 2005.

INSTITUTO ADOLFO LUTZ. Métodos físicos e químicos para análise de alimentos. São Paulo: ITAL, 1985. 533p.
JAYALEKSHMY, A.; ARUMUGHAN, C.; NARAYANAN, C. S.; MATHEW, A. G.Changes in the chemical composition of coconut water during maturation. Oléagineux, Paris, v.43, n.11, p.409414. 1998

LEITE, R. A. Uso de matrizes experimentais e de modelos estatísticos no estudo de equilíbrio fósforo-enxofre na cultura da soja em amostras de dois latossolos de Minas Gerais. 1984. 87f. Dissertação (Mestrado em Solos e Nutrição de Plantas) Universidade Federal de Viçosa, Viçosa, 1984.

MALAVOLTA, E. Importância da adubação na qualidade dos produtos/ função dos nutrientes na planta. In: SÁ, M. C. de.; BUZZETI, S. Importância da adubação na qualidade dos produtos agrícolas. São Paulo: Ícone, 1994. cap.1, p.19-44.

MALAVOLTA, E. VITTI, G. C; OLIVEIRA, S. A. de. Avaliação do estado nutricional das plantas. Piracicaba: POTAFOS, 1997.319p.

MIRANDA, F. R.; OLIVEIRA, V. H.; MONTENEGRO, A. A. T. Desenvolvimento e precocidade de produção do coqueiro anão ( Cocos Nucifera L. ) sob diferentes regimes de irrigação. Agrotrópica, Ilhéus, v.11, n.2, p. 71-76, 1999.

PESSARAKLI, M.; TUCKER, T. C. Dry matter yield and nitrogen-15 uptake by tomatoes and sodium chloride stress. Soil Science Society of American Journal, Washington, v.52, n.3, p. 698-700, 1988.

RICHARDS, J. D. Diagnosis and improvement of saline and alkali soils. Washington: United States of Department of Agriculture, 1954. 160p. (Agriculture handbook, 60).

ROSA JÚNIOR, C. D. R. M.; COSTA, F. F. da.; SILVA FILHO, A.V. da. Coqueiro: cultivo. In: ROSA, F. M.; ABREU, P. A. F. Água-decoco: métodos de conservação. Fortaleza: EMBRAPA - CNPAT / SEBRAE / CE, 2000. 40p. (Documentos, 37).

SOBRAL, L. F. Nutrição e adubação do coqueiro. In: FERREIRA, J. M. S; WARWICK, D. R. N; SIQUEIRA, L. A. (Ed.). A cultura do coqueiro no Brasil. Brasília: Embrapa, 1998. cap. 6, p. 129-157.

TAVARES, M.; CAMPOS, N.C.; NAGATO, L.A.F; LAMARDO, L.C.A.; INOMATA, E.L.; CARVALHO, M. F. H.; ARAGÃO, W.M. Estudo da composição química da água-de-coco-anão-verde em diferentes estágios de maturação. In: CONGRESSO BRASILEIRO DE CIÊNCIAETECNOLOGIADEALIMENTOS, 1998, Rio de Janeiro. Anais... Rio de Janeiro: SBCTA, 1998. v.2, p. 1262-1265.

TEIXEIRA, L.A.J.; BATAGLIA, O. C.; BUZETTI, S.; FURLANI JÚNIOR, E. Adubação com NPK em coqueiro-anão verde (cocos nucifera L.) - atributos químicos do solo e nutrição da planta. Revista Brasileira de Fruticultura, Jaboticabal, v. 27, p.115-119, 2005. 